
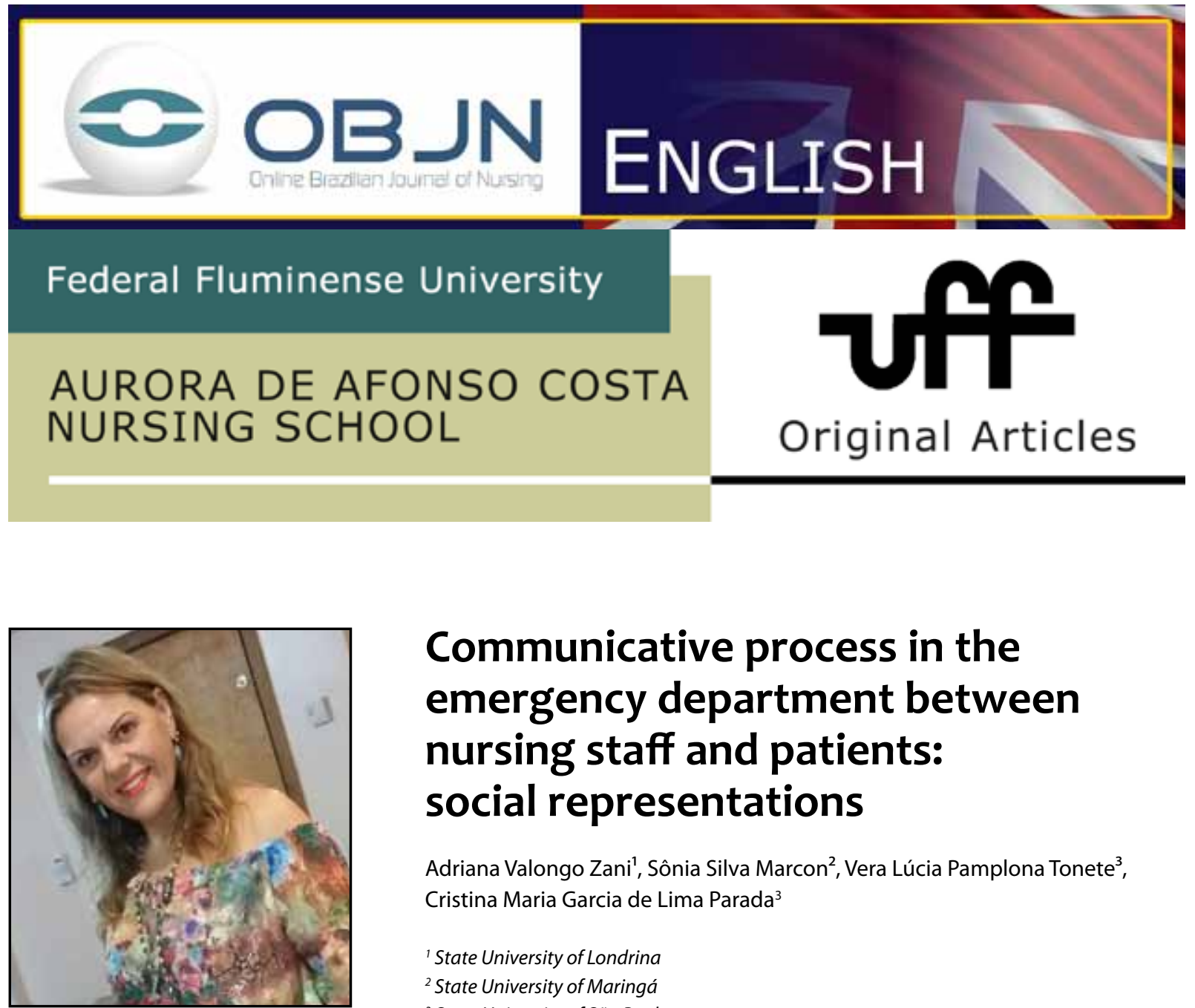

\title{
Communicative process in the emergency department between nursing staff and patients: social representations
}

\author{
${ }^{1}$ State University of Londrina \\ 2 State University of Maringá \\ ${ }^{3}$ State University of São Paulo
}

Adriana Valongo Zani', Sônia Silva Marcon², Vera Lúcia Pamplona Tonete ${ }^{3}$,

Cristina Maria Garcia de Lima Parada ${ }^{3}$

\section{RESUME}

Aim: To describe and analyze the communication process established between nursing professionals (nurses and nursing technicians) and patient/family in the ER, from the perspective of professionals and patients involved. Method: A qualitative approach based on the Theory of Social Representation was used. The sample was formed by 40 subjects; 20 nurses and 20 patients. Data were collected from May to June 2011 and, for the analysis, we used the methodological reference of the Collective Subject Discourse. Results: The interviews were grouped into two themes: communication between practitioner and patient/family and the importance of the communication process with the family for the patient's recovery. Discussion: The representations obtained were quite similar, especially when considering the difficulties of the communication process, and restricted when reducing it to guidance and information. Conclusion: We confirmed the relevance of communication with family in the recovery of patients.

Descriptors: Communication; Nursing; Patients; Family; Emergency Medical Services. 


\section{INTRODUCTION}

The term "communicate" comes from the Latin communicare and means, "to put in the common"(1). It is understood, from this definition, that it can be considered the comprehensive exchange of meaning through symbols, with (or presuming) a reciprocity in the interpretation of the message. Regardless of the communication mode, it is always present in the therapeutic scene, conveying conscious and unconscious content whose meaning is linked to the context in which it occurs ${ }^{(2)}$.

Communication is considered by health professionals as a basic tool for health care and is present in all actions performed with the patients / clients to guide, inform, support, comfort and meet their basic needs. Thus, it is one of the tools used to develop and refine the professional know-how, being especially relevant for facilitating quality care.

Care is a complex interaction between human beings, consisting of health actions and activities directed to patients and shared with them, involving dialogue, listening, help, return, support, comfort, discovery of the other, clarification of doubts, the cultivation of sensitivity and promotion, appreciation and mutual understanding ${ }^{(3)}$. It requires direct interaction between professional and patient which, in turn, depends on effective communication, and so the health professionals must use the proper techniques of interpersonal communication.

The importance of the family in the care when facing the illness of one of its members is widely known. Thus, it is commonly stated that, in the communication process established in situations of hospitalization, both the patient and their family must be considered.

The communication may occur verbally or non-verbally and may suffer interference in its development, resulting in difficulties in the caring and in the patient-provider relationship. It is a complex process, especially if the person is in hospital, in which the expectations about treatment and quality of care can interfere in its development and, consequently, in the recovery of the patient ${ }^{(4)}$.

Verbal communication is expressed by speech or writing and the non-verbal type involves manifestations of behavior not expressed in words, like gestures, silence, facial expressions and body posture. Aspects of nonverbal communication strongly influence human relations and must be observed in everyday life by workers dealing directly with people, such as health care professionals ${ }^{(5)}$.

Being competent in communication is a critical skill to be acquired by health professionals in general and in particular by the nursing professional, because it enables a conscious, true and transforming care ${ }^{(4)}$.

Considering the role of nursing professionals in health care and the importance of communication for its full development, especially when it involves urgency / emergency, we propose the present study, aimed to describe and analyze the communication process established between nursing professionals (nurses and technicians) and patient / family units in the $E R$, from the perspective of patients and professionals involved.

\section{METHOD}

We used a qualitative approach for this study. Qualitative research is understood as capable of incorporating both the meaning and intentionality as inherent to acts, relationships and social structures, the latter considered both in its advent as in their transformation as significant human constructions ${ }^{(6)}$. 
The study scenario consisted of the emergency room of a teaching hospital from the Unified Health System (SUS), a public institution in the state of Parana, which prioritizes the development of assistance, teaching and research activities. Because of its active operational capacity, it is ranked as a 'hospital size four', with units of medical-surgical and pediatrics, maternity, a surgical center, emergency room and adult, pediatric and neonatal intensive care units (ICU).

The emergency department of this institution serves an average of 110 patients per day, and is city reference for trauma care, receiving patients by risk classification in the specialties of orthopedics, surgery and obstetrics and gynecology. It is also a reference for cases of poisoning and accidents with venomous animals, for the occurrences from Mobile Medical Service (SAMU), the Emergency Trauma Care Integrated Service (SIATE) and referrals from basic health units, hospitals and cities comprising the $15^{\text {th }}$ health region of Paraná. It is noteworthy that despite being an emergency unit, hospitalizations of adults are common in this site.

The study included 40 subjects: 20 health professionals (nurses and nurse technicians) working in the emergency department and 20 patients admitted to the same department.

The subjects, personally invited by the researchers, were informed about the occupation and titration of the researchers and the research objectives, and after this the term of consent was presented and signed. Inclusion criteria: health professionals should be registered nurses or practical nurses and must be working in the ER service at the time of data collection. As for the patients, they should be admitted to the emergency room for treatment in the same collection period. Exclusion criteria were professionals who were just backing up emergency room professionals, but belonged to other units; and patients with less than 24 hours in the emergency department.

The average duration of a meeting of researchers with participants was around 45 minutes, including the initial interaction and the interview itself. The number of participants was not defined primarily, and data collecting finished when the concerns were answered and the study objective was attained.

The interviews were recorded, and a field notebook was used. At the end of the interview, the participants listened to their recordings and the researcher read the synthesis made in the field notebook so that they could agree or amend the information. The interviews of both professionals and patients occurred in offices that were unoccupied at the time, with some exceptions in the cases when the patients could not move around and the interview took place at the bedside.

Data collection was conducted from May to June 2011, through semi-structured interviews. It was considered that the interview is a process of social interaction, in which the interviewer aims to obtain information from the interviewee, by a script containing topics around a central problem ${ }^{(7)}$. Moreover, it favors the collecting of information through individual talks, which reveal structural conditions, value systems, norms and symbols and it transmits, through a spokesman, the representations of certain groups ${ }^{(6)}$.

The guiding questions used to motivate the speech of professionals were: How do you see the communication between you and the patient and/or family (easy/difficult points)? In which situations do you talk with the patient and/or family? Considering the communication process, how do you assess the presence of relatives in the emergency department? For patients: how would you rate the communication that occurs between you and the nurses 
who assist you? How would you like these professionals to talk to you about your health? Who talked to you and your family during hospitalization and what did they say?

The theoretical framework adopted for data analysis was the Social Representations Theory, an interpretation of reality that assumes that there is no distinction between subject and object of research, since all reality is represented by the individual. Thus, the representation is a global and unified view of an object, and, so that the individual can form such global views, it uses elements of everyday facts and knowledge of common sense ${ }^{(8)}$.

The social representation is expressed as a "form of socially elaborated and shared knowledge with practical significance that contributes to building a common reality to a certain social group"(9:609) where the research subject gives meaning to an object, starting from their own reality and/or experiences ${ }^{(9)}$. It is a philosophical expression that means the reproduction of a previous perception or the content of thought. So, it is expressed by collective representations; referring to the categories of thought a given society develops and expresses as its reality ${ }^{(6)}$.

The data was processed with the methodological framework of the Collective Subject Discourse (CSD). The proposal basically consists of CSD analysis of verbal material collected by extracting four methodological approaches from the speeches to organize, display and analyze data obtained through the interviews. The key-expressions consist of literal transcriptions from parts of the interviews, which allow the extraction of the essential in the discursive content; the central idea (IC) of a speech can be understood as the sentence or sentences that convey the essential content of the discourse; the CSD tries to reconstruct, from individual speech pieces, like a puzzle, as many synthetic discourses as necessary to express the thought or social representation of a group of people about a particular subject and it is built in the first person singular view; the anchoring is the explicit linguistic manifestation of a given theory, ideology or belief that the author of the speech can declare and, as a general statement, is being used by the enunciator to "frame" a specific situation(10). In this study, the first three figures have been developed.

The research was conducted with the assent of the local Research Ethics Committee (Opinion No. 111/2011) and fully complied with Resolution 196 of October 10 ${ }^{\text {th }}, 1996$, which approved the guidelines and rules for research involving human subjects ${ }^{(11)}$. To ensure the anonymity of the subjects, the nurses were identified by the letters PE and patients by the letter $P$, followed by the sequence number.

\section{RESULTS}

A brief characterization of the professionals shows that nurses were aged between 25 and 35 years and had an average experience in emergency rooms between 6 months and 5 years; nursing auxiliaries were aged between 35 and 55 years, and 5 to 20 years of work in emergency rooms. The patients' ages ranged between 18 and 65 years with hospitalization time ranging from 3 to 15 days.

For the analysis, the discourse of the professionals was grouped into two themes: communication between practitioner and patient/family and the importance of the communication process with the family to the patient's recovery, as shown below. 
Theme 1 - Communication between professional and patient/family

A negative and restricted view of the communicative process emerged from the discourses of professionals and patients, as can be seen in IC 1 to 3 :

\section{IC 1 - The communication does not occur properly}

CSD 1: I realize that due to the large number of patients, overwork, lack of staff members, sometimes we do not perform an adequate and continuous guidance, and mostly we just respond to what the family or the patient ask and we do not always make ourselves clear. In many situations our guidelines are inadequate and precarious (PE1-PE2, PE5, PE12, PE15, PE17, PE20).

CSD 2: In general, it is not that easy regarding the guidelines, since most of my clients, or my patients and family have a low socioeconomic and cultural background and the more I try to guide and use a most common and simple language I notice that they fail to understand the information and begin to ask over and over again on the same subject. (PE1-PE2, PE4, PE9-PE10, PE18).

CSD 3: I think another factor favoring the patient and family to have trouble understanding the information and guidance I provide them is that many patients are hospitalized for long periods, awaiting surgical procedures, because unfortunately we professionals have no way to determine the exact period they will need to wait. This ultimately leads to discontentment, anxiety and stress, which I believe could be a reason the patient and family cannot understand our guidelines. (PE1-PE3, PE7, PE9-PE10, PE18-PE20).

\section{IC 2 - Professionals provide false information}

DSC 4: Many professionals do not make themselves clear; they use words I do not know, give false information, saying that I'm leaving and then another one comes and says no, I'll have to operate. They often do not know how long I'll need to stay in hospital and when they'll will solve my problem, or why they're taking so long to solve it... (P1, P6, P7, P9, P11, P14, P17, P18, P20).

\section{IC 3 - No information about hospital routines}

CSD 5: Actually, I have received no information about the hospital routines. Whenever I need something, I have to ask. I only know the visiting hours because I took the information sheet there in reception, but I don't know anything about the rest. Oh, I also know that you cannot bring food from home, because one day my family brought and they didn't let them in, said it was the hospital regulations. (P2, P3, P4, P8, P10, P12, P15, P16, P19).

In contrast, the DSC 6, drawn from the speech of patients, reveals a favorable position regarding the communication process with the nursing staff: 
IC4 - Information is clear and easy to understand

CSD 6: The information I received from health professionals, especially the nurse, in many situations was clear and I could understand; they can explain in a way that is easier to understand (P1, P2, P3, P5, P6, P8, P13, P19).

IC 5 and 6 are related to the discussion of communication applied situations.

IC5 - Information is provided in all situations, from admission to discharge

CSD 7: I usually provide guidelines in relation to the clinical status of the patient in the emergency room, talk about the interventions he/she will undergo or has already been submitted to; I guide the family about how to obtain information about test results and verify the situation of the patient on the waiting list for surgery or transfers to other services, i.e., I try to provide information in all situations, from admission to discharge (PE1, PE3, PE5, PE7, PE8).

IC6 - Information is provided about procedures only

CSD 8: The situations in which I specifically provide information to the patient and/or family are: in the case of fasting for surgery or examination, situations related to the preparation for the exams, patients referred for procedures outside the hospital, and the cases I will perform procedures on them such as dressings, venous punctures and/or surveys (PE1, PE3, PE5, PE9, PE11, PE13, PE16-PE17).

Theme 2 - The relevance of the communication process with the family for the patient's recovery

In general, communication with the family was considered positive, with the potential to aid in the recovery of patients, especially in situations of increased dependence and at discharge, as evidenced by IC 7 to 9:

IC 7 - The family presence is positive and important for care

CSD 9: The presence of family with the patient in the emergency department, generally, is positive and important, because it helps both the nursing staff and the patient, especially in cases of weaker patients. The fact that the patient has a companion allows that person to relate the care provided by nursing staff and other professionals to their ill family member (PE1, PE3, PE5, PE17, PE20).

CSD 10: The companion provides comfort and safety to patients mainly by giving psychological and emotional support, something that health professionals, due to the demand for labor and the small number of professionals, fail to perform (PE5, PE7, PE17-PE19).

CSD 11: The companion helps the patient in simple procedures such as oral hygiene, bathing and feeding, helps to take him to the bathroom, encourages walking when it's allowed, helps the patient to get out of bed, sit in a chair and change clothes (PE1-PE2, PE4-PE5, PE7). 
IC8 - The companion is a way to store some information

CSD 12: I seek first to analyze the patient: age, diagnosis. When I have some announcement to make I request the presence of a companion. As in the situation of discharge, in which the patient is dependent and will have to go with an enteral tube, for example, I request support from social and nutrition services, so that we can guide this family together in the preparation and administration of the diet and to the care with the probe. I believe that the guidelines provided are important because they will help the family to take care of their patient in both the hospital and especially in their home (PE1, PE2, PE5, PE9, PE11).

IC9 - Communication between family and staff improves the care

CSD 13: When the family remains together with the patient, this fact allows them to resolve their doubts and makes it easier for the family, at the time of discharge, to feel safer when taking care of the patient at home, and also ensures that the family quickly assimilates the guidance provided by health professionals (PE1, PE3, PE5-PE6, PE8).

CSD 14: They (the companions) assist the nursing team, providing information about the patient's history, warning about changes in the patient's condition where nursing staff is not in the room at that moment, warn of procedures such as medication or serum completed, when the patient is in pain and needs medication or even in situations where there is need for change or care of bedridden patients (PE9, PE12, PE14-PE15, PE17-PE19).

In contrast, in speech number 15 , the professionals presented negative aspects related to the presence of the family which, in their perception, may remain in the hospital not only attending to their relative:

IC 10 - Parallel conversations disturb the hospital environment

DSC 15: There are some situations in which the family can hinder patient care, particularly when they do not allow certain precautions and procedures, or when the companion, rather than staying next to their sick relative providing care and/or keeping him company, chooses to walk the halls of the units talking with other patients and families, disrupting the hospital environment (PE5-PE6, PE12, PE17, PE20).

\section{DISCUSSION}

It is known that the expectations people have in relation to hospitalization, treatment and quality of care are factors that can interfere with their recovery ${ }^{(4)}$. Nursing care is an act of interaction, consisting of actions and activities directed to patients and shared with them, involving dialogue, listening, help, return, support, comfort and clarification of doubts, cultivating sensitivity, discovery, appreciation and understanding of others. From this perspective, communication can contribute to an effective, therapeutic action that does not only heal the body but also brings comfort to the spirit. 
The act of caring, which brings into context the objectivity of a technique and the subjectivity of the creation, can encourage nursing staff to reflect and genuinely look to the patient's life, improving the quality for those who are physically or emotionally dependent on it. It is in the everyday care that a patient/ familiar dialogic relationship can result in support, balance and well-being ${ }^{(4)}$.

In this study an intrinsic part of care, the communication with the patient and family, was linked to orientation, making the guiding process ideal as a continuum, but pointing out as real only the answer to the questions, not always in a clear way. It is certain, however, that the family and the patient expect the professional is ready to provide them with the information that may alleviate their anxieties and doubts, but the process of communication should not be limited to this.

The responses also indicate that verbal messages emitted by the professionals are not always understood by the patient/family. In the response, reflection on the process of communication arises, with any possible failure being assigned to the last consideration.

It is emphasized that the difficulties of communication with patients/companions are often cited by nursing staff and, as a way to protect themselves, nursing technicians tend to provide the least amount of information possible, requesting the presence of nurses in many of the interactions required ${ }^{(12)}$. Another aspect to be considered is that, for some nurses, the social, economic and cultural differences have been perceived as communication barriers. Furthermore, patients cite communication with nurses as effective when compared with other professionals in the area of health.

The communication between the nursing staff and the inpatient family deserves attention, because there is still a significant lack of knowledge about clinical progress by the relatives. The right of family to information about the clinical and psychological condition of their relative, though assured by the Code of Ethics for Professional Nursing and the Brazilian Constitution, does not always occur ${ }^{(12)}$. Recalling that the purpose is to enable the health professional and patient/family delineating the needs to be met, to help people being treated feel that they are decent human beings, with autonomy to solve their own problems in order to promote and maintain their physical and mental health, as well as find new patterns of behavior if faced with an unexpected situation.

With regard to the patients, they expect health professionals to provide them with accurate information about their health condition/disease. However, the perception that this information is unclear or contradictory generates discontent and anxiety about the treatment they are receiving.

Although the daily communication is essential for the exercise of professional practice, aspects that impact negatively on the interaction between health professionals and patients are observed. Work overload, lack of time, the priority given to the work routines over the interaction with the patient, lack of training and the exclusion of the family in the process of care for the patient, are negative aspects ${ }^{(12)}$.

From what the patients say, it is also evident that there are problems, even when considering the transmission of basic, simple and trivial information for professionals, and it is extremely necessary and important for the patient and family to understand the hospital dynamics. Knowing the routines of the hospital contributes to the preparation of patients to experience their condition in a hospital emergency room, a situation that can generate fear and anxiety. 
Therefore, it is necessary for the nurse to perform care management and also cover the actions aiming towards the proper functioning of the unit and consequently minimize the difficulties of interaction between the patient, family and professional in a hospital ${ }^{(13)}$.

Family and inpatients have specific needs, including those related to communication and, when not met, they can cause stress, mood disorders and anxiety.

The physical environments for the restoration of health, such as hospitals, in general lack an appropriate treatment that makes them recognizable as healthy environments. One cause of this problem is related to the difficulty of hospital environments to provide clear and objective information to its users; in this case, patients and families. On the other hand, listening to criticism, suggestions and demands of these users can lessen the negative aspects and reveal important data to be incorporated in its routines and norms and thus contribute to the environments assuming the condition of health promoters ${ }^{(14)}$.

The study revealed the importance of the communication process with the family for the patient's recovery. It is known that for the human being, disease is the breakdown of its organic harmony, interfering with all parts of its life and affecting even the living with the closest family members. When hospitalization is necessary, the individual is removed from their home environment and taken to a completely strange world where strict rules and routines can control and determine his actions ${ }^{(15)}$.

Patients often report that the hospital environment is unknown and aggressive, where they suffer due to a forced change of diet and hydration, the fear of dying, dependence on others, disrespect regarding their privacy and lack of individualized attention ${ }^{(3)}$. In this context, their recovery may be delayed, which has caused hospitals to accept or even encourage the presence of accompanying family members.

In addition to supporting the patient, the family can provide the information needed for better care, since it decodes tastes, mannerisms and expressions of patients with impaired verbal communication. This data can be essential to nursing $\operatorname{care}^{(3)}$.

The close contact of the family with the hospitalized relative is good for the patient and it also reduces the feeling of powerlessness in face of that individual's suffering ${ }^{(3)}$. It is noteworthy that the family should, and it has legal protection to this, be informed of the health of their relative, and may actively participate in the patient care process. The nursing staff, recognizing this role, must insert them effectively into the communication process.

We should also consider that, for the family members, it may be difficult to get out of their everyday routine and experience the illness of someone close. Then it must be up to the services to promote a favorable environment where the patient and family feel the peace and confidence to experience the right of being together, while allowing the companion to identify, feel, learn, choose and decide on ways of acting in this environment, without negative interference in the organization of health services.

Regarding the need for hospitalization, especially in situations of emergency rooms, patients' families need support and should not be seen as a "technical" aid to nursing work, but as individuals to be maintained. To allow them to fulfill their role of supporting the situation experienced by the patient, they also need support in their physical and emotional needs, as an enlightening conversation, as the possibility of having an extra chair which facilitates contact with their loved one, or even as the offering 
of a meal at a more critical time, among other actions that demonstrate hospitality.

In this study, communication was also linked to the orientation of biological aspects of care, recognizing the division of labor in the professional specialties, and assigning to the worker the role of informant, and to the patient/ family that of the receiver of the message.

Good communication must be understood as the receipt of information of what the individual wants to know; to ask questions and get answers and receive news. It is essential that the professional understands what the family is asking and vice versa ${ }^{(3)}$.

In summary, the family and the well-being of its members and evidence of its positive role in health recovery has forced institutions and professionals to consider the humanized, family-centered, care as part of the health care practice $^{(16)}$.

\section{CONCLUSION}

This study revealed that the representations of patients and professionals working in an ER unit share similarities in some aspects, especially in considering the difficulties inherent in this process and their perception in a specific way: the professionals identified it as guidance and patients as received information. The enlargement of this design is a challenge to be assumed, especially by nursing professionals.

Among the representations of the professionals about the communication process, the families stood out, particularly in relation to their possible contribution to the recovery of the patient. In this sense, it is for professionals and services to seek effective communication with the family, in order to enhance their role.

\section{REFERENCES}

1. Oriá MOB, Moraes LMP, Victor JF. A comunicação como instrumento do enfermeiro para o cuidado emocional com o cliente hospitalizado. Rev. Eletr. Enf. [Internet]. 2008 [cited 2011 December 10]; 11(6): 292-5. Available from: http:// www.revistas.ufg.br/index.php/fen/article/ view/808/921.

2. Ramos AP, Bortagarai FM. A comunicação não-verbal na área da saúde. Rev. CEFAC. [Internet]. 2011. [cited 2011 July 08] jan/fev; 14(1): 164-70. Availabre from: http://www.scielo. $\mathrm{br} / \mathrm{scielo}$.php?script=sci_arttext\&pid=S1516$-18462011005000067 \&$ lng $=$ pt.

3. Inaba LC, Silva MJP, Telles SCR. Paciente crítico e comunicação: visão de familiares sobre sua adequação pela equipe de enfermagem. Rev Esc Enferm USP. 2007; 39(4):423-9.

4. Razera APR, Braga EM. A importância da comunicação durante o período de recuperação pós-operatória. Rev. esc. enferm. USP. 2011; 45(3): 632-637.

5. Rossi-Barbosa LAR et al . A percepção de pacientes sobre a comunicação não verbal na assistência médica. Rev. bras. educ. Med. 2010; 34(3): 75-80.

6. Minayo MCS. O desafio do conhecimento. Pes-

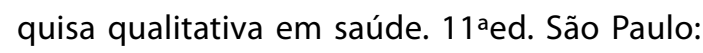
HUCITEC/ABRASCO, 2008.

7. Haguette TMF. Metodologias qualitativas na sociologia. 12a.ed. Petrópolis: Vozes; 2010.

8. Oliveira DC, Sá CP. Representações sociais da saúde e doença e implicações para o cuidar em enfermagem: uma análise estrutural. Rev Bras Enferm, 2011 out/dez; 54(4): 608-22.

9. Reis $C B$, Andrade SMO. Representação social do trabalho em equipe na atenção à mulher sob a ótica da enfermeira. Esc. Anna Nery. 2008 jan/ mar; 12(1): 50-6.

10. Lefèvre F; Lefèvre AMC. Pesquisa de Representação Social. Um enfoque qualiquantitativo. São Paulo: Liberlivro; 2011.

11. Conselho Nacional de Saúde (Brasil). Resolução no 196 de 10 de outubro de 1996. Aprovar as diretrizes e normas regulamentadoras de pes- 
quisas envolvendo seres humanos. Diário Oficial da União 10 out 1996, seção 1.

12. Casanova EG, Lopes GT. Comunicação da equipe de enfermagem com a família do paciente. Rev Bras Enferm 2009; 62(6): 831-6.

13. Santos J.Silva M.Klock P.Erdmann A. Conceptions of Nurses on Management of Care in an Emergency Department- Descriptive Exploratory Study Online Brazilian Journal of Nursing [serial on the Internet]. 2012 April 18; [Cited 2012 May 14]; 11(1). Available from: http://www.objnursing. uff.br/index.php/nursing/article/view/3580.

14. Grossman E, Araujo-Jorge TC, Araujo IS. Sensitive listening: a study on the relationship between people and health environments. Interface Comunic., Saúde, Educ. 2008 abr/jun; 12(25): 309-24.

15. Paula AAD, Furegato ARF, Scatena MCM. Interação enfermeiro-familiar de paciente com comunicação prejudicada. Rev.latino-am.enfermagem. 2008 ago; 8(4): 45-51.

16. Soares M. Cuidando da Família de Pacientes em Situação de Terminalidade Internados na Unidade de Terapia Intensiva. Revista Brasileira de Terapia Intensiva, 2007 out-dez; 19(4): 481-84.

Authors contribution: Conception and design: all; Analysis and Interpretation: all; Article writing: all; Critical review and final approval: Adriana Valongo Zani.
All authors participated in the phases of this publication in one or more of the following steps, in According to the recommendations of the International Committee of Medical Journal Editors (ICMJE, 2013): (a) substantial involvement in the planning or preparation of the manuscript or in the collection, analysis or interpretation of data; (b) preparation of the manuscript or conducting critical revision of intellectual content; (c) approval of the versión submitted of this manuscript. All authors declare for the appropriate purposes that the responsibilities related to all aspects of the manuscript submitted to OBJN are yours. They ensure that issues related to the accuracy or integrity of any part of the article were properly investigated and resolved. Therefore, they exempt the OBJN of any participation whatsoever in any imbroglios concerning the content under consideration. All authors declare that they have no conflict of interest of financial or personal nature concerning this manuscript which may influence the writing and/or interpretation of the findings. This statement has been digitally signed by all authors as recommended by the ICMJE, whose model is available in http://www.objnursing.uff.br/normas/DUDE_eng_1306-2013.pdf

Received: 09/04/2012

Revised: 04/13/2014

Approved:04/09/2014 